\title{
Effects of Small Ni Addition on the Microstructure and Toughness of Coarse-Grained Heat-Affected Zone of High-Strength Low-Alloy Steel
}

\author{
Gang Huang ${ }^{1}$, Xiangliang Wan ${ }^{1, *}$, Kaiming $\mathrm{Wu}^{1, *}$, Huazhong Zhao ${ }^{2}$ \\ and Raja Devesh Kumarmr Misra ${ }^{3}$ \\ 1 The State Key Laboratory of Refractories and Metallurgy, Hubei Province Key Laboratory of Systems Science \\ in Metallurgical Process, International Research Institute for Steel Technology, Wuhan University of Science \\ and Technology, Wuhan 430081, China; huanggang@wust.edu.cn \\ 2 Wuhan Anchor Welding consumables Co., Ltd., Wuhan 430081, China; hzzhao@163.com \\ 3 Department of Metallurgical and Materials Engineering, University of Texas at El Paso, \\ El Paso, TX 79968, USA; dmisra2@utep.edu \\ * Correspondence: wanxiangliang@wust.edu.cn (X.W.); wukaiming@wust.edu.cn (K.W.); \\ Tel.: +86-27-68862772 (X.W. \& K.W.); Fax: +86-27-68862606 (X.W. \& K.W.)
}

Received: 14 August 2018; Accepted: 11 September 2018; Published: 13 September 2018

check for updates

\begin{abstract}
The objective of the present study is to investigate the effects of nickel $(\mathrm{Ni})$ on the microstructure and impact toughness of coarse-grained heat-affected zone (CGHAZ) of high-strength low-alloy steel. It was observed that the microstructure of CGHAZ predominantly consisted of bainite and a small proportion of martensite-austenite (M-A) constituents and acicular ferrite (AF). With increased Ni content, the percentage of M-A constituent decreased and AF increased; consequently, the impact toughness of CGHAZ increased. The study revealed that a small addition of nickel significantly affected the formation of M-A constituents and AF; however, no obvious influence was observed on the bainitic microstructure of high-strength low-alloy steel.
\end{abstract}

Keywords: high-strength low-alloy steel; Ni; coarse-grained heat-affected zone; microstructure; impact toughness

\section{Introduction}

High-strength low alloy steels (HSLA) are widely used in applications requiring welding because of their high toughness, high strength, cold formability, and good weldability. In recent years, several studies have been carried out using high heat input welding to reduce cost and improve welding efficiency. However, the high heat input welding thermal cycle results in a coarse-grained heat-affected zone (CGHAZ), as well as degradation in the toughness of steels [1]. Therefore, improvement in the toughness of HAZ is an important aspect when high heat input is used.

The toughness of HAZ is strongly influenced by the microstructural features of steels [2]. Coarse bainite in the HAZ of HSLA steel contains parallel bainitic ferrite and martensite-austenite (M-A) constituents [3]. Thus, it is difficult to obtain superior HAZ toughness because of the hard M-A constituents and the low-angle grain boundary between parallel bainitic ferrite, which facilitates nucleation and propagation of cracks. Previous studies have revealed that the microstructural features of HAZ greatly depend on the alloying elements in HSLA steels [4]. Deoxidizing alloying elements, such as titanium and zirconium, provide favorable nucleation sites at grain boundaries for AF during the welding thermal cycle [5]. Some studies have also proposed that niobium, aluminum, and silicon can modify the morphology of M-A constituents [6-8]. 
Nickel (Ni) is generally present as a solid solution strengthening element in ferrite and increases the strength of steel by solid solution strengthening. Ni also has a strong influence on the toughness of weld metals. Previous studies have indicated that with increasing Ni content, the microstructure of the weld metal can be refined [9]. However, when Ni content exceeds a certain value, the toughness of the weld metal is reduced because of the formation of martensite [10]. Superior low-temperature toughness in high-Ni steel can be obtained due to the retained austenite, which absorbs high energy by transformation of the retained austenite to strain-induced martensite during Charpy impact testing [11]. However, an understanding of the effect of $\mathrm{Ni}$ on microstructural transformation and impact toughness of CGHAZ of HSLA steels is relatively limited and requires in-depth study.

In the present study, the effect of $\mathrm{Ni}$ on microstructural transformation during the welding thermal cycles of HSLA steels was studied, and the underlying toughening mechanism of CGHAZ was also explored.

\section{Experimental Procedure}

Three steel samples, Ni-free, $0.23 \% \mathrm{Ni}$, and $0.43 \% \mathrm{Ni}$ steel, were prepared in a $10 \mathrm{~kg}$ vacuum melt induction furnace (Jinzhou North Electric Furnace Factory, Jinzhou, Liaoning, China) (Table 1). The cylindrical ingots, $120 \mathrm{~mm}$ in diameter and $100 \mathrm{~mm}$ in length, were reheated to $1250 \pm 20^{\circ} \mathrm{C}$ and forged into rectangular billets with cross-sections $30 \mathrm{~mm} \times 30 \mathrm{~mm}$. The samples were then machined into dimensions of $11 \mathrm{~mm} \times 11 \mathrm{~mm} \times 100 \mathrm{~mm}$. The simulation of CGHAZ was carried out using a Gleeble 3800 (Dynamic Systems Inc., Austin, TX, USA). A schematic diagram of simulated thermal cycles is presented in Figure 1.The peak temperature, heating rate, and holding time for thermal cycle simulation were $1350{ }^{\circ} \mathrm{C}, 300{ }^{\circ} \mathrm{C} / \mathrm{s}$, and $3 \mathrm{~s}$, respectively. The cooling times from $800{ }^{\circ} \mathrm{C}$ to $500{ }^{\circ} \mathrm{C}\left(\mathrm{t}_{8 / 5}\right)$ were $10.6 \mathrm{~s}$ and $52.8 \mathrm{~s}$, respectively, which were approximately equivalent to heat inputs of $20 \mathrm{~kJ} / \mathrm{cm}$ and $100 \mathrm{~kJ} / \mathrm{cm}$, respectively [12,13].

Table 1. The chemical composition of the investigated steels (wt.\%).

\begin{tabular}{cccccccccc}
\hline Sample & $\mathbf{C}$ & $\mathbf{S i}$ & $\mathbf{M n}$ & $\mathbf{N b}$ & $\mathbf{N i}$ & $\mathbf{T i}$ & $\mathbf{M o}$ & $\mathbf{A l}$ & $\mathbf{F e}$ \\
\hline Ni-free & 0.054 & 0.19 & 1.56 & 0.038 & - & 0.012 & 0.020 & 0.022 & Bal. \\
$0.23 \% \mathrm{Ni}$ & 0.056 & 0.20 & 1.58 & 0.036 & 0.23 & 0.015 & 0.019 & 0.025 & Bal. \\
$0.43 \% \mathrm{Ni}$ & 0.052 & 0.22 & 1.55 & 0.037 & 0.43 & 0.014 & 0.018 & 0.024 & Bal. \\
\hline
\end{tabular}

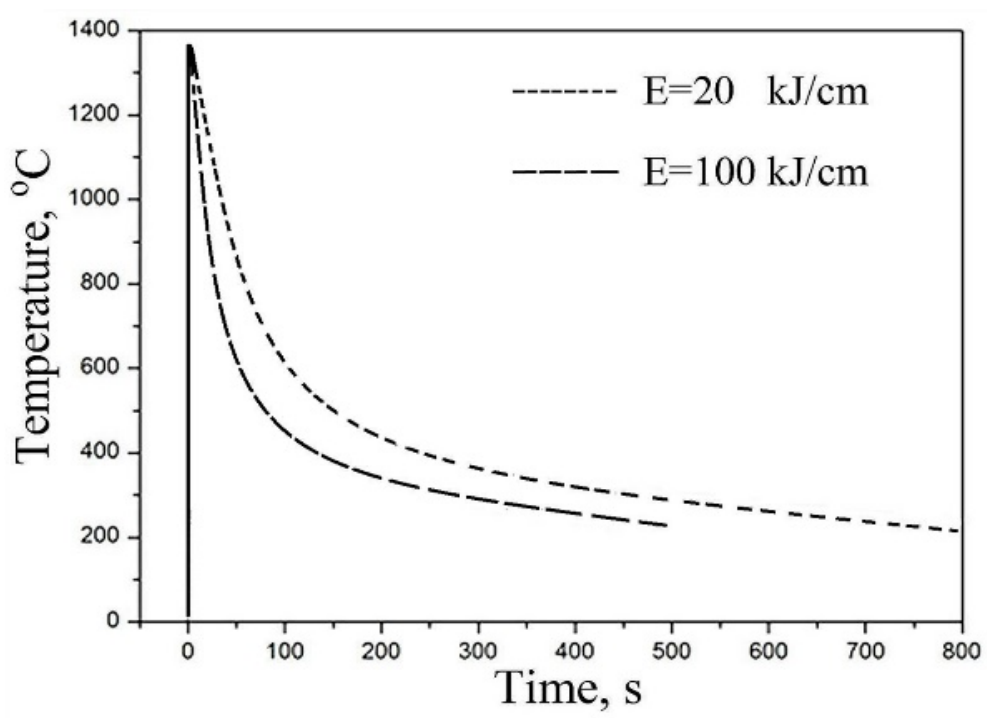

Figure 1. Schematic illustration of simulated thermal cycles of the CGHAZ.

After the simulation, standard Charpy v-notch specimens of dimensions $10 \mathrm{~mm} \times 10 \mathrm{~mm} \times 55 \mathrm{~mm}$ were machined for Charpy impact test at $-20^{\circ} \mathrm{C}$. The microstructure and fracture surface of the 
samples were studied by optical microscope (OM, Olympus Corporation, Tokyo, Japan.) and scanning electron microscope (SEM, FEI, Boston, MA, USA). The crystallographic grain size and the grain boundary misorientation were analyzed by electron backscattered diffraction (EBSD, EDAX, New York, NJ, USA) technique. The M-A constituents and AF grains in the digital images of simulated CGHAZ were selected and painted black using Adobe Photoshop (version 6.0, San, Jose, CA, USA) (Figure 2). The length, width, density, and area percentage of M-A constituents and AF grains were estimated using Image-Pro Plus (version 6.0, MEDIA, Rockville, MD, USA). Thirty digital images were analyzed to obtain an average value of the above parameters $[12,13]$.

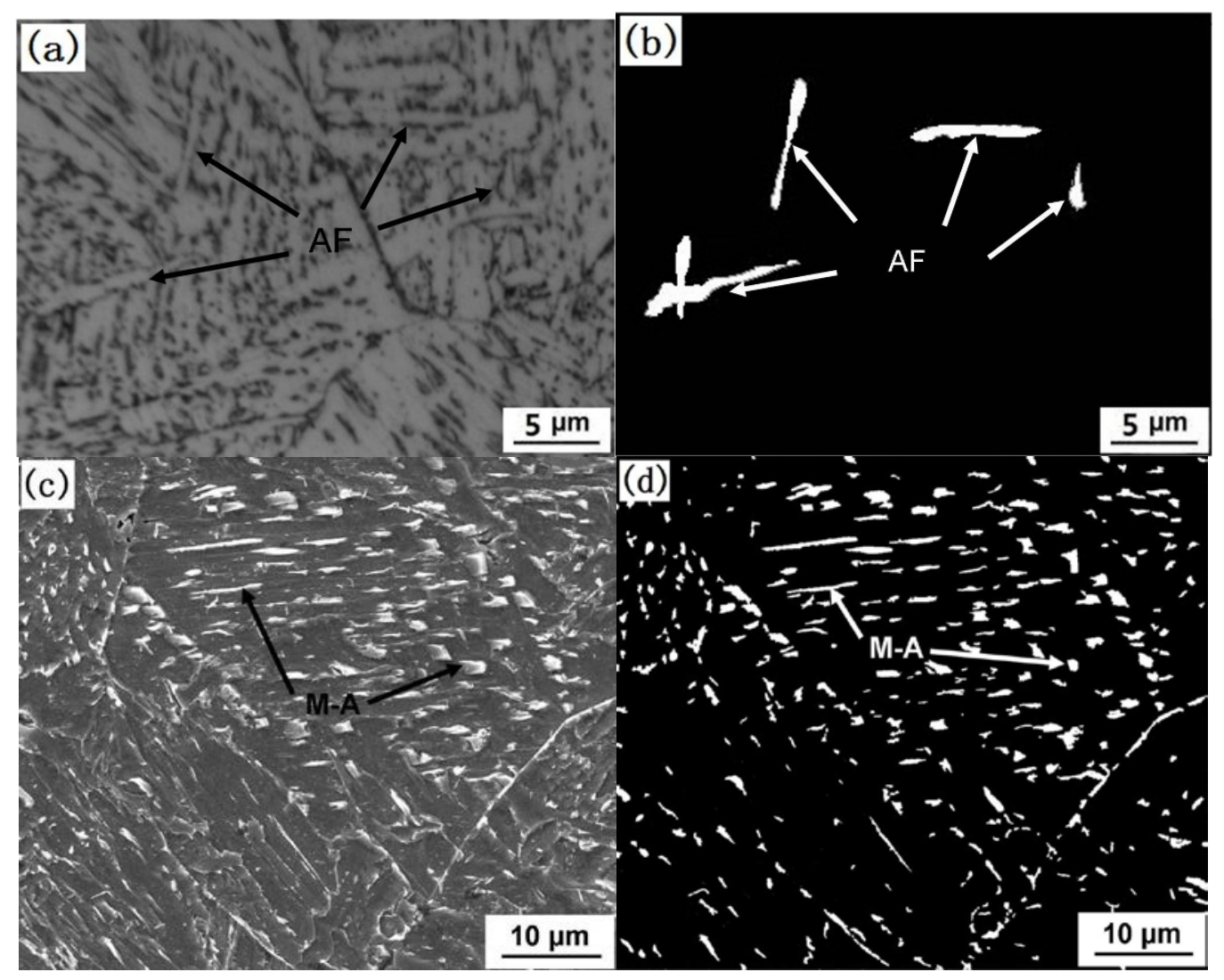

Figure 2. (a) Optical and (c) SEM images showing representative acicular ferrite and M-A constituents, respectively, in the simulated CGHAZ of Ni-free steel with $100 \mathrm{~kJ} / \mathrm{cm}$ heat input welding thermal cycle. $(\mathbf{b}, \mathbf{d})$ are processed images of $(\mathbf{a}, \mathbf{c})$, respectively, using Adobe Photoshop.

\section{Results}

\subsection{Microstructural Characteristics of Simulated CGHAZ}

Figure 3 shows the optical micrographs of simulated CGHAZ for three steel samples. It was observed that the prior austenite grains became coarse in all the samples. The microstructure of all the samples predominantly consisted of bainite and a small percentage of AF and M-A constituents. The AF grains were scattered among prior austenite grains, and some of them were also associated with inclusions. The bainitic ferrite sheaves nucleated at the grain boundaries and grew into the interior of the grain. Furthermore, the M-A constituents were observed in bainite packets, as well as between the boundaries of bainite packets. 


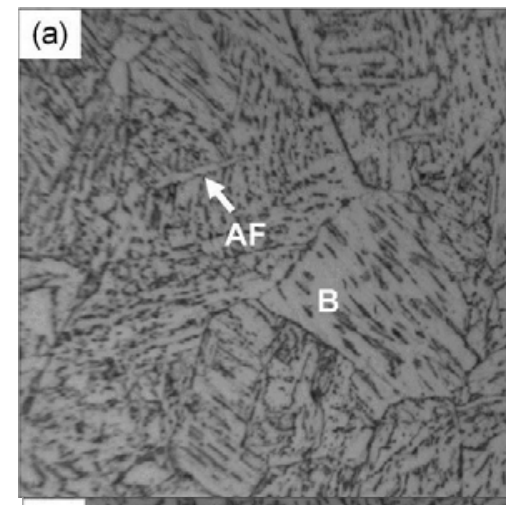

(c)
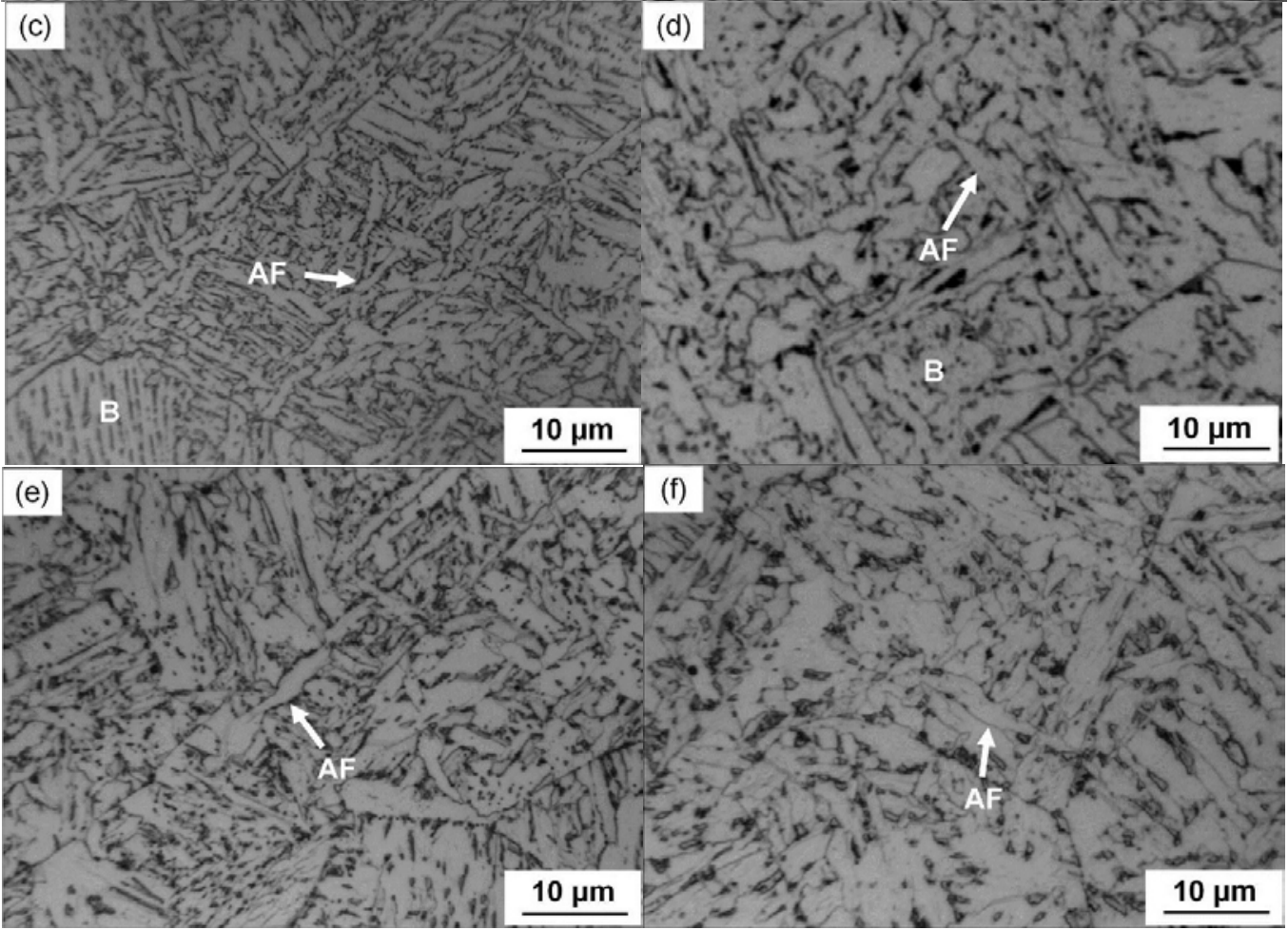

Figure 3. Optical micrographs of simulated CGHAZ in specimens (a,b) Ni-free, (c,d) $0.23 \% \mathrm{Ni}$, and $(\mathbf{e}, \mathbf{f}) 0.43 \% \mathrm{Ni}$, with heat input of $(\mathbf{a}, \mathbf{c}, \mathbf{e}) 20 \mathrm{~kJ} / \mathrm{cm}$, and $(\mathbf{b}, \mathbf{d}, \mathbf{f}) 100 \mathrm{~kJ} / \mathrm{cm}$, respectively.

\subsection{Quantitative Analysis of Microstructure of Simulated CGHAZ}

Prior austenite grain size is crucial for microstructural evolution [14]. The size of prior austenite grains was measured by averaging the long and short axes of the grains. The mean equivalent diameters and standard deviation of prior austenite grains (taken from about 20 optical micrographs at $500 \times$ magnification) are presented in Figure $4 \mathrm{a}$. The equivalent diameters of prior austenite grains were in the range of $55-60 \mu \mathrm{m}$ at $20 \mathrm{~kJ} / \mathrm{cm}$ heat input welding, and increased to $70-80 \mu \mathrm{m}$ for $100 \mathrm{~kJ} / \mathrm{cm}$. However, no significant change was noticed with increased Ni content (Figure 4a). 
(a)
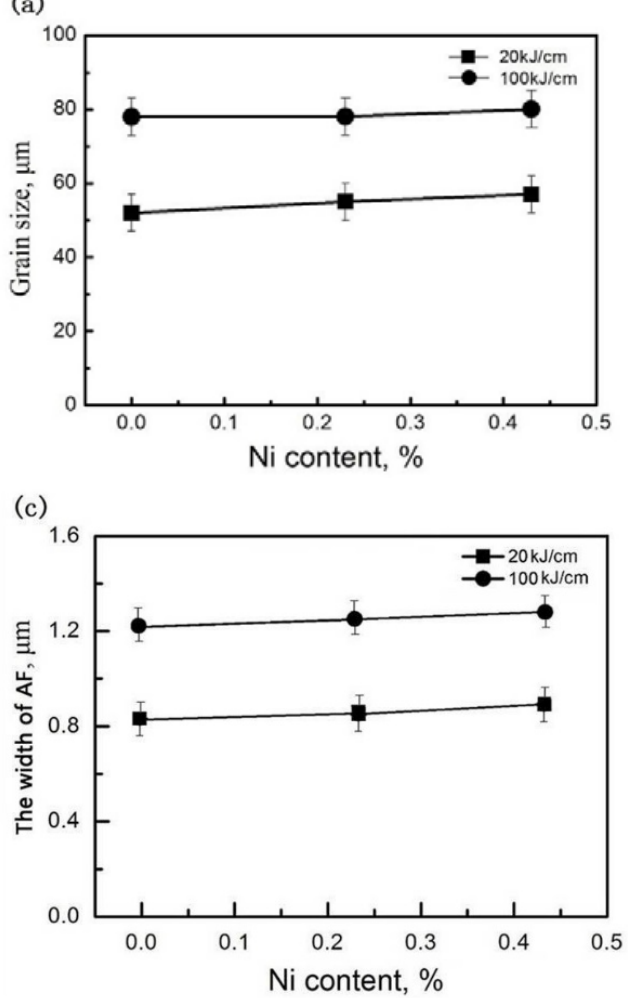
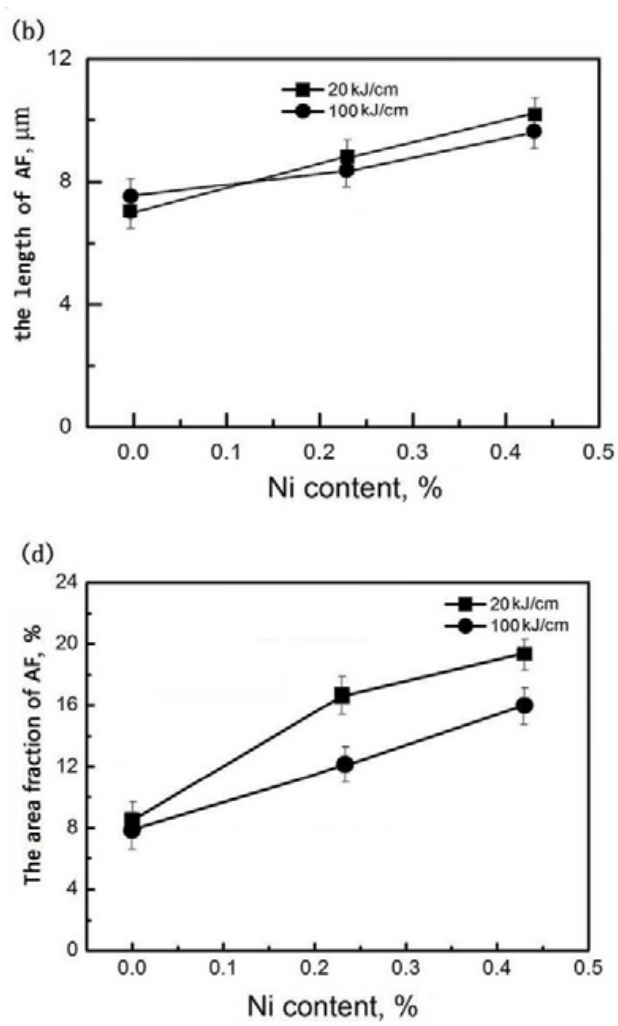

Figure 4. (a) Prior austenite grain size and (b) mean length, (c) width, and (d) area percentage of acicular ferrite in samples subjected to different heat inputs.

$\mathrm{AF}$ is one of the most important constituents for improving the toughness of CGHAZ of HSLA steels [3]. The mean length, width, and area percentage of AF was measured (Figure $4 b-d)$. The mean length and width of AF increased with increased Ni content (Figure $4 b, c)$. The area percentage of AF also increased with increased Ni content and heat input (Figure $4 \mathrm{~d}$ ).

Figure 5 shows the SEM images of block-like and film-like M-A constituents in the simulated CGHAZ. It is noted that the size, density, and area percentage of M-A constituents varied with increased Ni content and heat input (Figure 6). The mean length of M-A constituents decreased with increased Ni content (Figure 6a); however, the density of M-A constituents did not change with increased Ni content (Figure 6b). It was observed that the area percentage of M-A constituents also decreased with increased Ni content (Figure 6c). Previous studies reported that M-A constituents with large length $(>2 \mu \mathrm{m}$ and small length/width ratio $(<4)$ were regarded as block M-A constituents, and were detrimental to impact toughness [15]. It is evident from Figure $6 \mathrm{~d}$ that the area percentage of block M-A constituents decreased with increased Ni content.

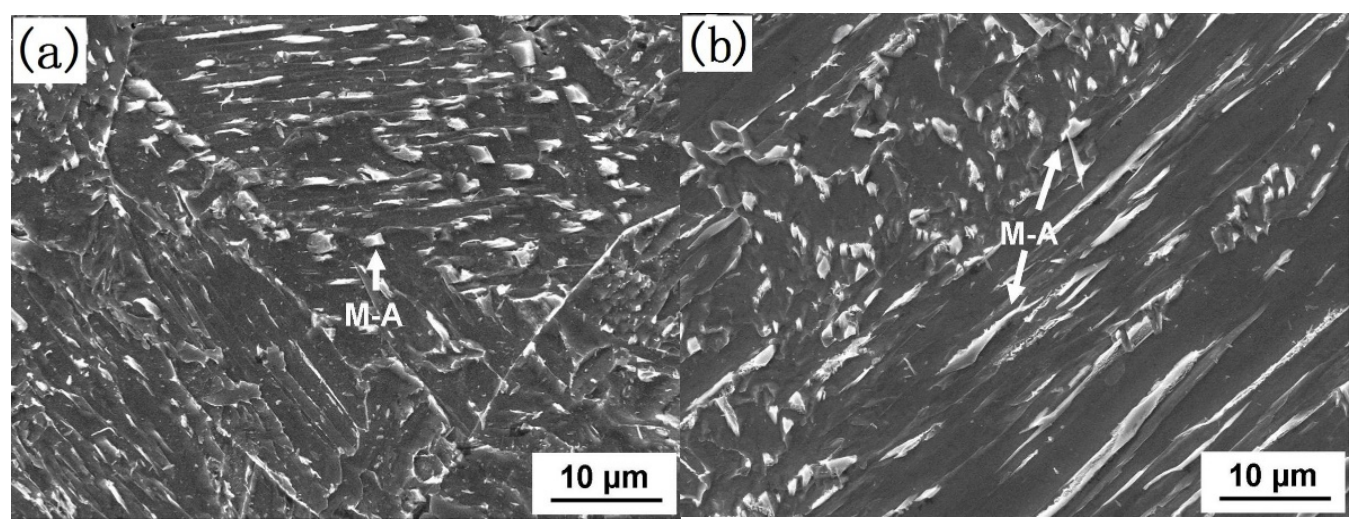

Figure 5. Cont. 


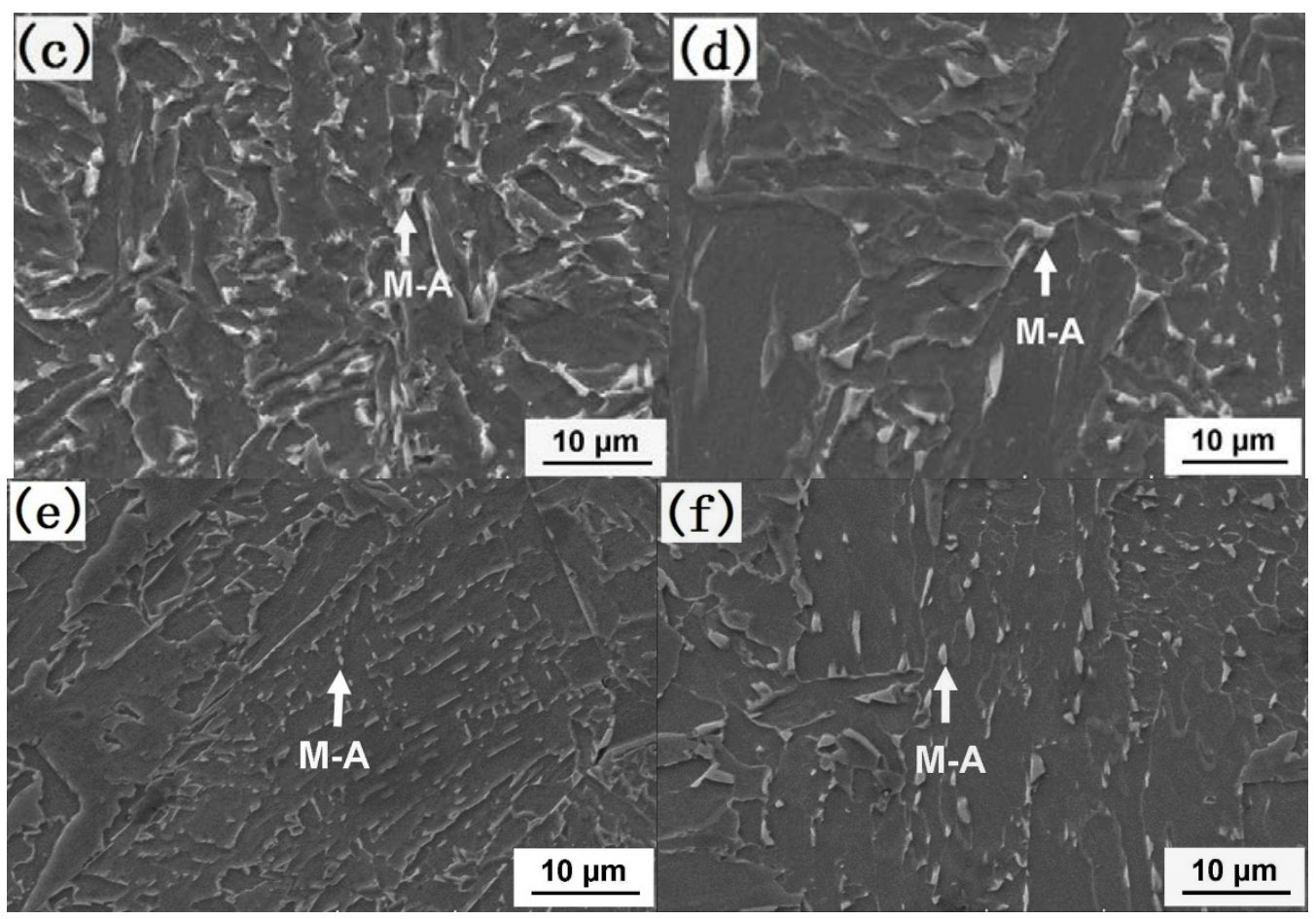

Figure 5. SEM images of the simulated CGHAZ in (a,b) Ni-free, (c,d) $0.23 \% \mathrm{Ni}$, and (e,f) $0.43 \% \mathrm{Ni}$ steels subjected to the heat input of $(\mathbf{a}, \mathbf{c}, \mathbf{e}) 20 \mathrm{~kJ} / \mathrm{cm}$ and $(\mathbf{b}, \mathbf{d}, \mathbf{f}) 100 \mathrm{~kJ} / \mathrm{cm}$.

(a)

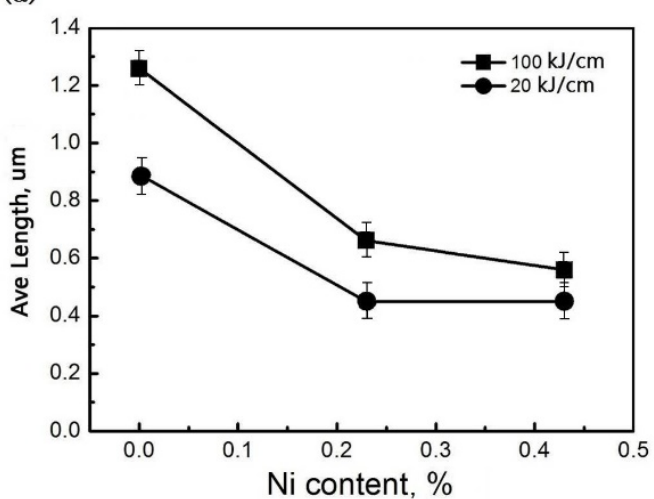

(c)

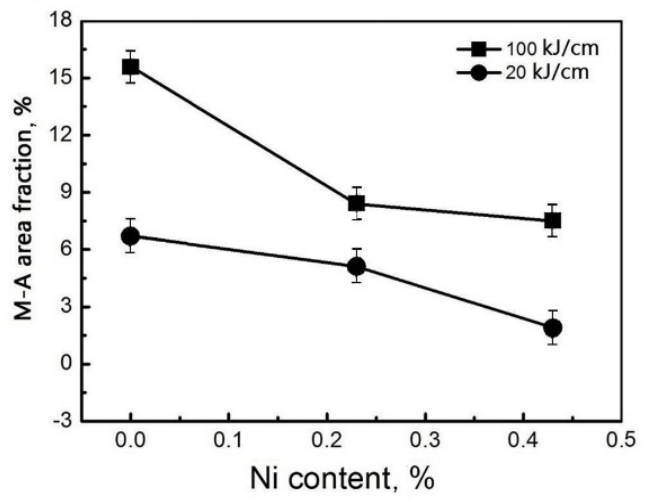

(b)

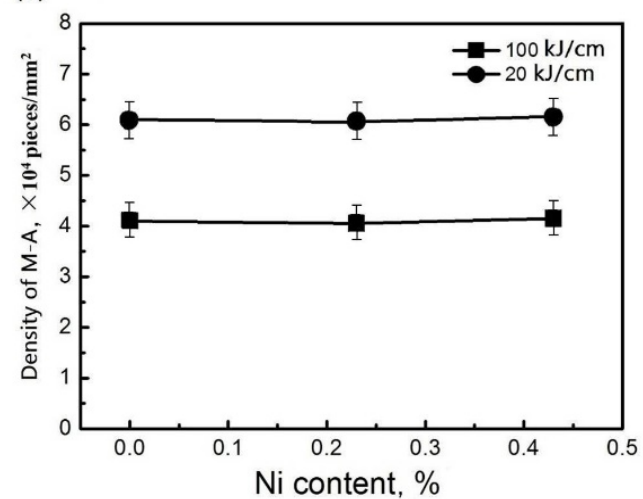

(d)

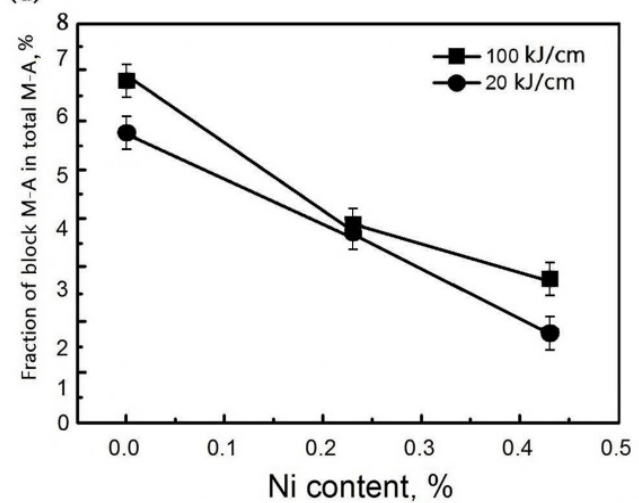

Figure 6. Effect of nickel content and simulated heat input on (a) mean length, (b) density, and (c) area percentage of M-A constituent, and (d) area percentage of block M-A in the CGHAZ. 


\subsection{EBSD Analysis and Grain Size Determination of Simulated CGHAZ}

Figure 7 presents the EBSD analysis of simulated CGHAZ for $100 \mathrm{~kJ} / \mathrm{cm}$ heat input welding. Figure $7 \mathrm{a}-\mathrm{c}$ is the corresponding EBSD orientation image maps of $\mathrm{Ni}$-free, $0.23 \% \mathrm{Ni}$, and $0.43 \% \mathrm{Ni}$ steel, respectively. Different bainite packets are represented by different colors and characterized by high-angle grain boundaries between the packets with large misorientations $\left(50^{\circ}-60^{\circ}\right)$. The bainitic ferrite laths/plates (for low-angle grain boundaries) in the same bainite packet are represented by similar color. However, it was observed that AF grains grew in the interior of prior austenite grains and had different orientations with the neighboring ferrite plates.
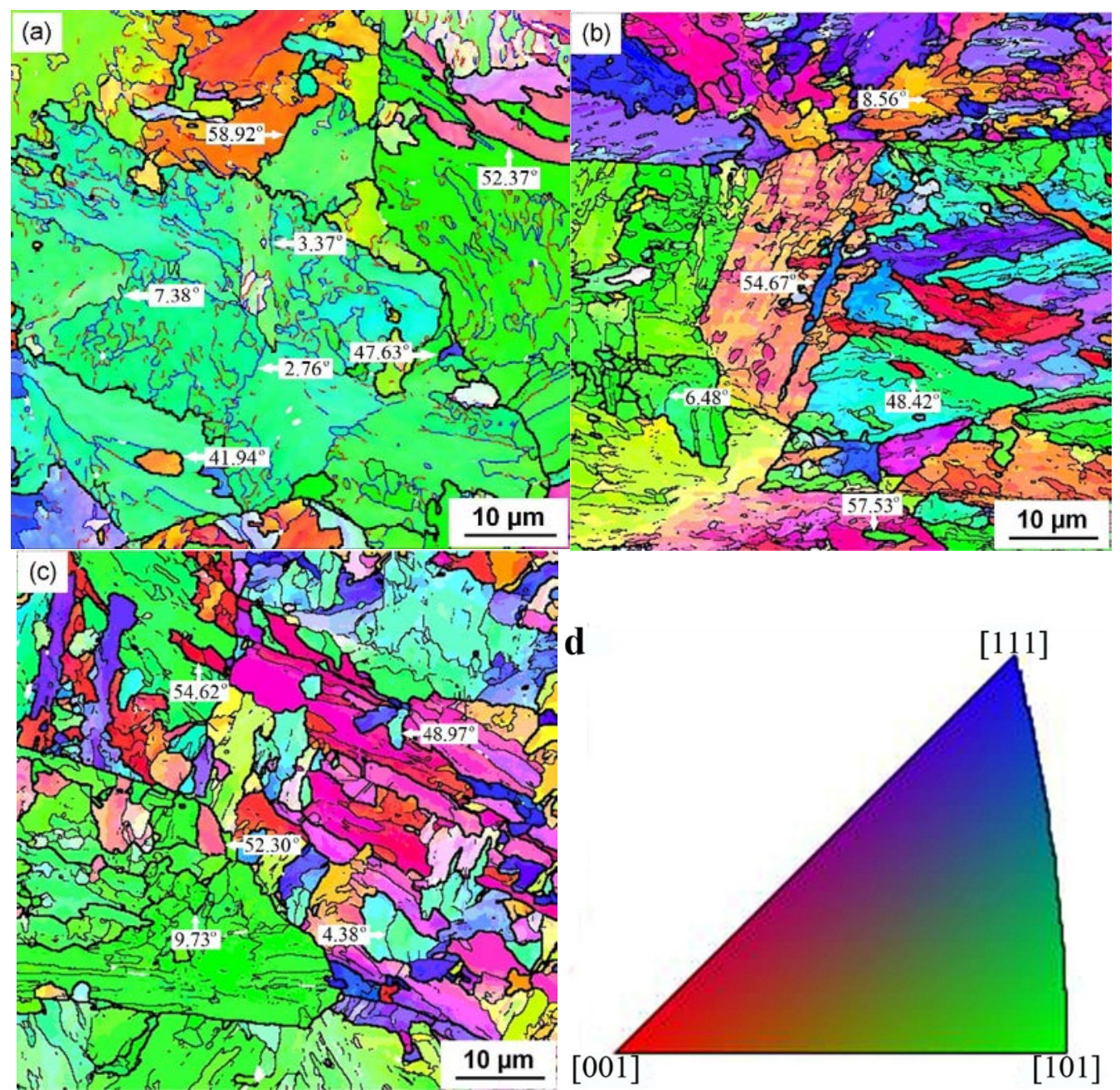

Figure 7. Orientation maps of bcc phase of steel samples. (a) Ni-free, (b) $0.23 \% \mathrm{Ni}$, and (c) $0.43 \% \mathrm{Ni}$; and (d) orientation color key. The simulated heat input for all samples is $100 \mathrm{~kJ} / \mathrm{cm}$.

Figure 8a, billustrates the distribution of grain boundary misorientation angles between adjacent grains. The frequency of high-angle grain boundaries $\left(45^{\circ}-62^{\circ}\right)$ for Ni-free steel was smaller than for $0.23 \% \mathrm{Ni}$ and $0.43 \% \mathrm{Ni}$ steels (Figure $8 \mathrm{~b}$ ). In the present study, the high-angle grain boundary threshold was estimated at $15^{\circ}$; hence, grain boundaries with a misorientation larger than $15^{\circ}$ were regarded as the boundary of two grains. Grains were assumed to be spherical to facilitate grain size measurement. Figure $8 \mathrm{c}$ displays the statistical distribution of crystallographic grain size. The mean crystallographic grain sizes in CGHAZ of Ni-free, $0.23 \% \mathrm{Ni}$, and $0.43 \% \mathrm{Ni}$ steels were calculated as $9.4 \mu \mathrm{m}, 4.9 \mu \mathrm{m}$, and $4.4 \mu \mathrm{m}$, respectively (Figure $8 \mathrm{~d}$ ), and these values were significantly smaller than those for the prior austenite grains $(73 \mu \mathrm{m}, 78 \mu \mathrm{m}$, and $80 \mu \mathrm{m}$ for Ni-free, $0.23 \% \mathrm{Ni}$, and $0.43 \%$ Ni steels, respectively), implying grain refinement in $\mathrm{Ni}$-containing steels. The percentages of grain refinement 
in prior austenite grains for $0.23 \% \mathrm{Ni}, 0.43 \% \mathrm{Ni}$, and $\mathrm{Ni}$-free steels were $\sim 94 \%$ (15.9 times finer), $95 \%$ (18.6 times finer), and $\sim 87 \%$ (7.7 times finer), respectively.
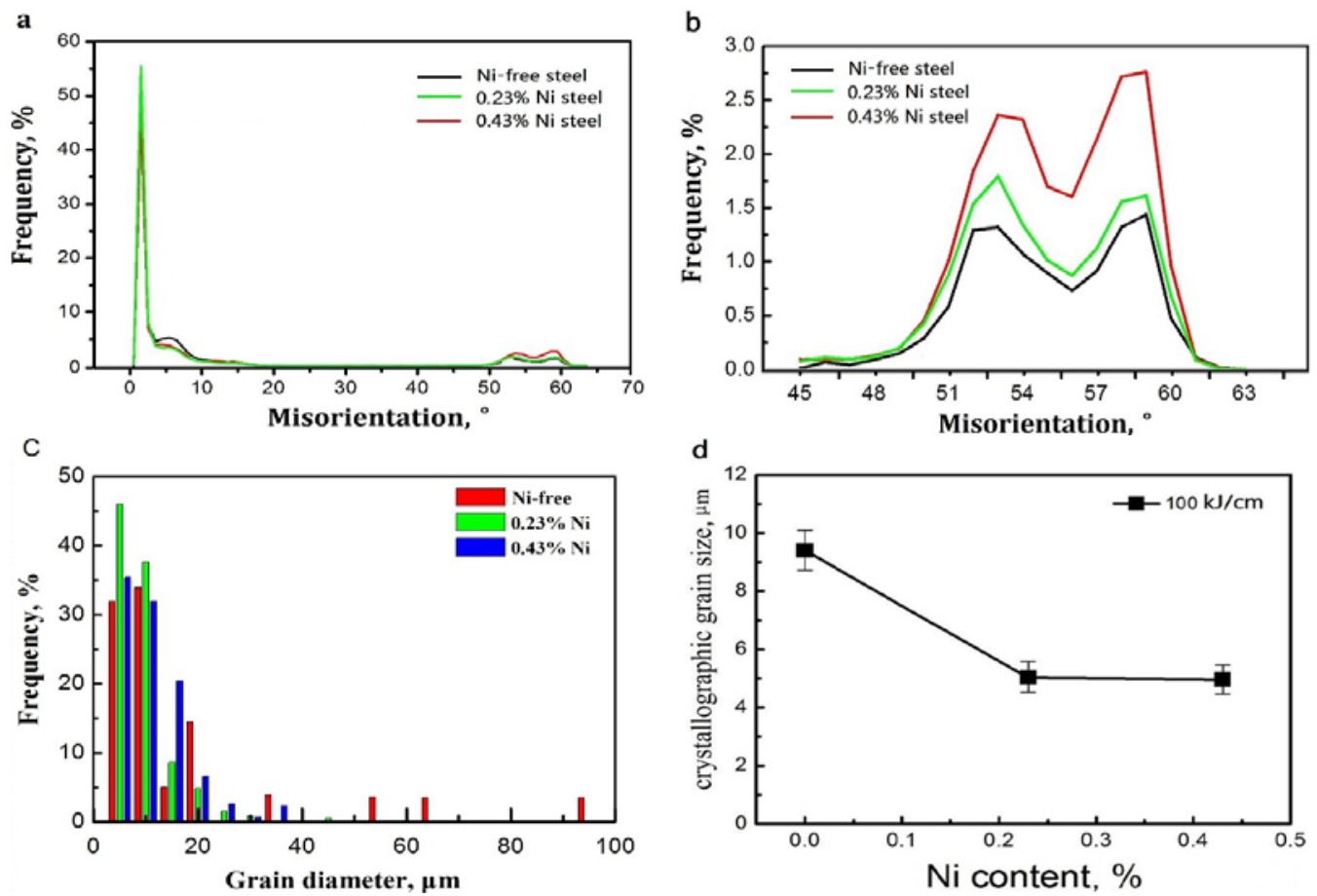

Figure 8. Statistical distribution of $(\mathbf{a}, \mathbf{b})$ misorientation between adjacent grains and (c) crystallographic grain size; and (d) mean crystallographic grain size of simulated CGHAZ.

\subsection{Impact Toughness in the Simulated CGHAZ}

The Charpy v-notch impact toughness of CGHAZ for samples with varying heat inputs is presented in Figure 9. It was observed that the average absorbed energy increased with increased $\mathrm{Ni}$ content for both heat input welding thermal cycles $(20 \mathrm{~kJ} / \mathrm{cm}$ and $100 \mathrm{~kJ} / \mathrm{cm})$. The average absorbed energy for the $20 \mathrm{~kJ} / \mathrm{cm}$ thermal cycle increased gradually from $94 \mathrm{~J}$ to $252 \mathrm{~J}$ and from $297 \mathrm{~J}$ for $0.23 \%$ and $0.43 \%$ Ni steels, respectively.

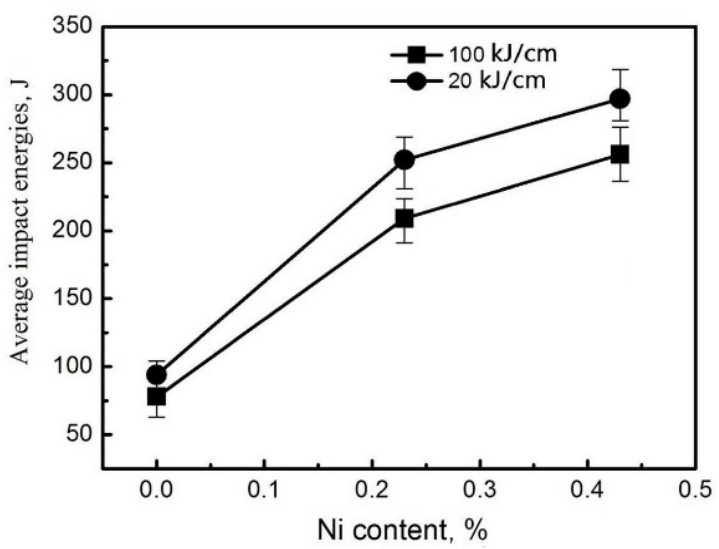

Figure 9. Effect of nickel content and simulated heat input on average impact energy at $-20{ }^{\circ} \mathrm{C}$ in the simulated CGHAZ.

Figure 10 displays the characteristics of impact fracture for all samples with varying $\mathrm{Ni}$ content and heat inputs. The fracture surfaces of Ni-free steel exhibited river pattern characteristic of quasi-cleavage fracture (Figure 10a,b). In contrast, the impact fracture surface of $0.23 \% \mathrm{Ni}$ and $0.43 \% \mathrm{Ni}$ steels consisted 
of dimples (Figure 10c-f). Therefore, the difference in the nature of the fracture surface can be attributed to transition in the fracture mechanism from quasi-cleavage to dimple fracture [16].

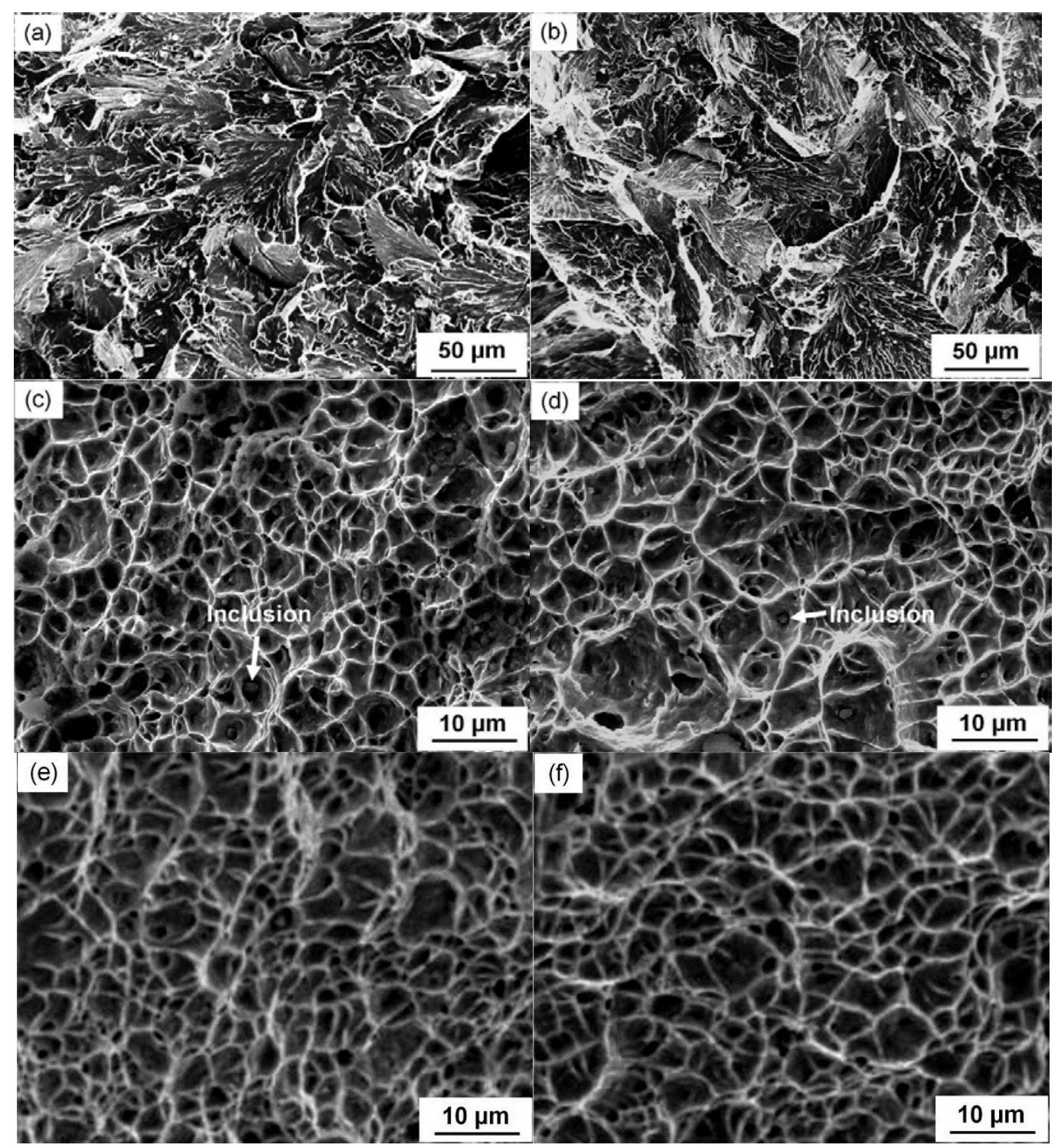

Figure 10. SEM images of impact fracture surface of simulated specimens. (a,b) Ni-free, (c,d) $0.23 \% \mathrm{Ni}$ and $(\mathbf{e}, \mathbf{f}) 0.43 \% \mathrm{Ni}$ for heat input of $(\mathbf{a}, \mathbf{c}, \mathbf{e}) 20 \mathrm{~kJ} / \mathrm{cm}$ and $(\mathbf{b}, \mathbf{d}, \mathbf{f}) 100 \mathrm{~kJ} / \mathrm{cm}$.

\section{Discussion}

\subsection{The Effect of Ni Addition on AF Formation and Impact Toughness}

$\mathrm{AF}$, also known as intragranular bainite, is the predominant microstructure in the CGHAZ of HSLA steels [3]. The formation of AF is strongly affected by the chemical composition of steel, inclusions, isothermal temperature, continuous cooling rate, and austenite grain size [4]. In the present study, the inclusion content, cooling rate, and prior austenite grain size were similar for three steels. The frequencies of AF grains in $0.23 \% \mathrm{Ni}$ and $0.43 \% \mathrm{Ni}$ steels were relatively higher in comparison to $\mathrm{Ni}$-free steel because of the different $\mathrm{Ni}$ content. Nickel can also decrease bainite start $\left(\mathrm{B}_{\mathrm{S}}\right)$ and bainite finish $\left(\mathrm{B}_{\mathrm{f}}\right)$ transformation temperature in steel [4]. Figure $11 \mathrm{a}-\mathrm{c}$ shows the continuous cooling curves of three steels for different cooling rates, which were calculated using J-MatPro software. The $\mathrm{B}_{\mathrm{s}}$ and $\mathrm{B}_{\mathrm{f}}$ temperatures for the samples cooled at a cooling rate of $6^{\circ} \mathrm{C} / \mathrm{s}$ (similar to $100 \mathrm{~kJ} / \mathrm{cm}$ heat input simulated welding) were selected (Figure $11 \mathrm{~d}$ ). It was discerned that $\mathrm{B}_{\mathrm{s}}$ transformation temperature 
decreased from $596{ }^{\circ} \mathrm{C}$ to $589^{\circ} \mathrm{C}$ with increased Ni content. Thus, the higher degree of supercooling induced an increase in Gibbs free energy and nucleation efficiency of AF. A previous study suggested that AF grains grow faster at lower temperatures [17]; hence, the percentage of AF increased with increased Ni content.
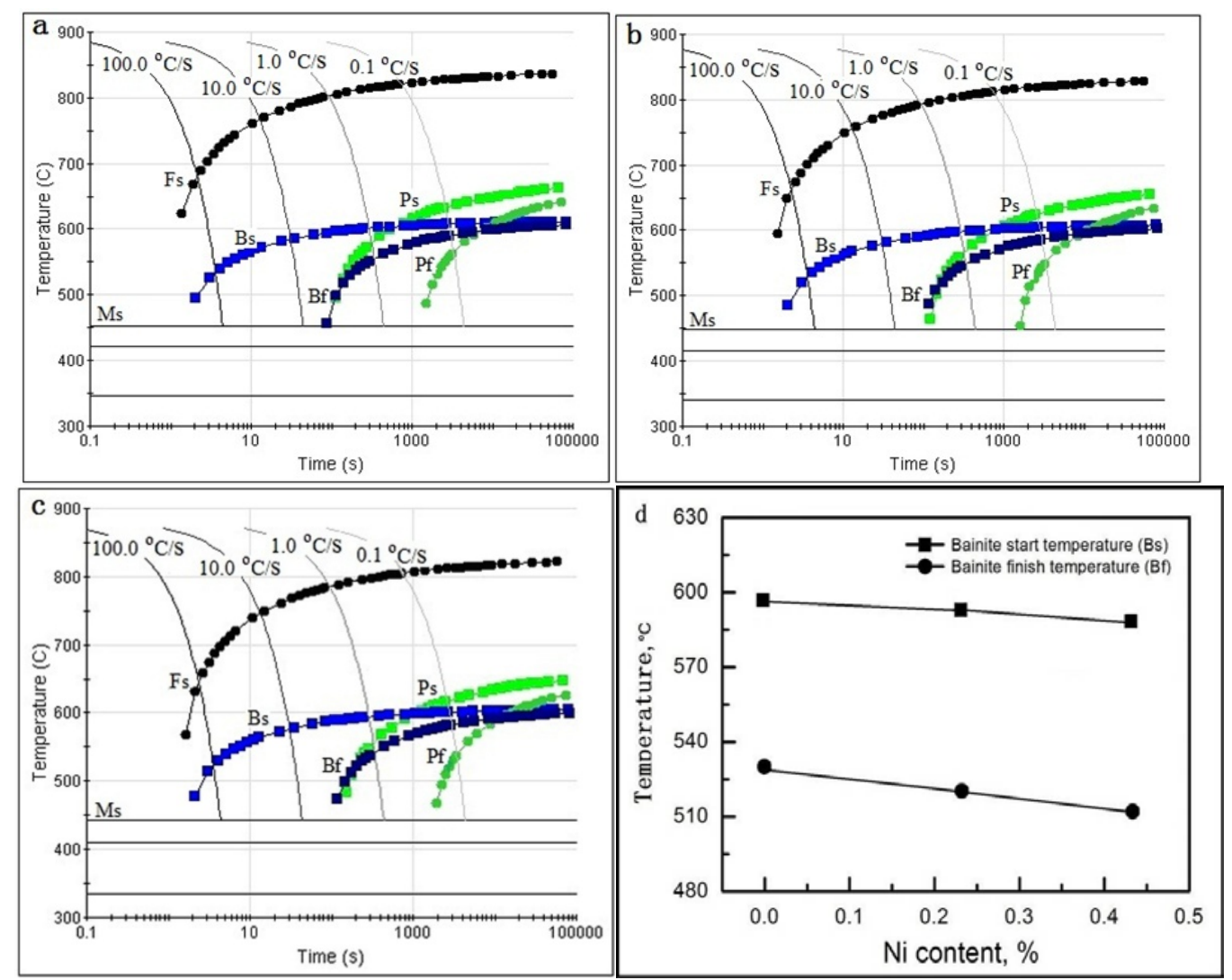

Figure 11. Calculated continuous cooling curves prepared by using J-MatPro for (a) Ni-free, (b) $0.23 \%$ $\mathrm{Ni}$ and (c) $0.43 \% \mathrm{Ni}$ steels, and (d) $\mathrm{B}_{\mathrm{s}}$ and $\mathrm{B}_{\mathrm{f}}$ temperatures of three samples with acooling rate of $6{ }^{\circ} \mathrm{C} / \mathrm{s}$. The $\mathrm{F}_{\mathrm{s}}, \mathrm{B}_{\mathrm{s}}, \mathrm{B}_{\mathrm{f}}, \mathrm{P}_{\mathrm{s}}, \mathrm{P}_{\mathrm{f}}$, and $\mathrm{M}_{\mathrm{s}}$ indicate ferrite start, bainite start, bainite finish, pearlite start, pearlite finish and martensite start transformation temperature, respectively.

AF microstructure with high-angle boundaries can enhance the toughness of HSLA steels by deflecting the propagation of cleavage crack [18]. In the present study, the frequency of AF grains in $0.23 \% \mathrm{Ni}$ and $0.43 \% \mathrm{Ni}$ steels was observed to be relatively higher than in Ni-free steel. Moreover, AF effectively refined the prior austenite grains in the CGHAZ. Thus, the formation of high-density AF grains in $0.23 \% \mathrm{Ni}$ and $0.43 \% \mathrm{Ni}$ steels contributed to a higher percentage of grain refinement. In addition, the average diameter of crystallographic grains was lower in $0.23 \% \mathrm{Ni}$ and $0.43 \% \mathrm{Ni}$ steels than in Ni-free steel. Furthermore, because of the fine-grained microstructure of AF, the cracks were less mobile and their direction of propagation was able to change during the Charpy v-notch impact test [18]. It can therefore be inferred that $0.23 \% \mathrm{Ni}$ and $0.43 \% \mathrm{Ni}$ steels possessed higher impact toughness in comparison to Ni-free steel.

\subsection{The Effect of Ni Addition on M-A Constituents and Impact Toughness}

M-A constituents have a significant influence on the toughness of HAZ [15]. Carbon diffuses into the untransformed austenite in CGHAZ, and these untransformed austenite areas become carbon enriched and are transformed into hard and brittle M-A constituents during continuous cooling [4]. Subsequently, microcracks are easily nucleated at the boundaries between M-A constituents and ferrite matrix. These cracks further propagate into the matrix when the stress concentration exceeds the 
critical stress of M-A constituents [4]. In the present study, SEM analysis revealed the presence of M-A constituents in bainite matrix (Figure 5). Moreover, the area percentage of M-A constituents decreased with increased $\mathrm{Ni}$ content. This finding is not in agreement with the previous result that showed an increase in M-A constituents with increased Ni content in high-strength steel [4]. The calculation of continuous cooling transformation also demonstrated that the temperature gap between $\mathrm{B}_{\mathrm{s}}$ and $\mathrm{B}_{\mathrm{f}}$ increased from $67^{\circ} \mathrm{C}$ to $77^{\circ} \mathrm{C}$ (from Ni-free to $0.43 \% \mathrm{Ni}$ steel) (Figure 11d). Thus, more austenite was transformed into bainitic ferrite and AF. Also, the amount of M-A constituents was lower in $0.23 \% \mathrm{Ni}$ and $0.43 \%$ Ni steels, and thereby contributed to high impact toughness in CGHAZ.

\section{Conclusions}

(1) The microstructure of simulated CGHAZ in the three steel samples with heat input of $20-100 \mathrm{~kJ} / \mathrm{cm}$ predominantly consisted of bainite and a small proportion of AF and M-A constituents. Although the small addition of $\mathrm{Ni}$ showed no significant effect on bainitic microstructure, it significantly influenced the formation of AF and M-A constituents. The area percentage of AF and M-A constituents in the simulated CGHAZ increased and decreased with increased Ni content, respectively.

(2) The impact toughness of simulated CGHAZ at $-20{ }^{\circ} \mathrm{C}$ increased with increased Ni content because of the fine-grained microstructure with more AF and fewer M-A constituents.

Author Contributions: K.W. conceived, X.W. and G.H. designed the experiments; G.H. performed the experiments and wrote the manuscript; H.Z. supplied the raw materials and R.D.K.M. revised the grammar of the manuscript.

Funding: The Major Technology Innovation of Hubei Province under grant (No. 2016AAA022); the National Natural Science Foundation of China (No. 51501134); China Postdoctoral Science Foundation (No. 2014M550414).

Acknowledgments: The authors gratefully acknowledge the financial support from the Major Technology Innovation of Hubei Province under grant No. 2016AAA022 and the National Natural Science Foundation of China (No. 51501134) and China Postdoctoral Science Foundation (No. 2014M550414).

Conflicts of Interest: The authors declare no conflict of interest.

\section{References}

1. Kojima, A.; Yoshii, K.; Hada, T.; Saeki, O.; Ichikawa, K.; Yoshida, Y.; Shimura, Y.; Azuma, K. Development of high HAZ toughness steel plates for box columns with high heat input welding. Nippon Steel Technol. Rep. 2004, 90, 39-44.

2. Bhadeshia, H.; Honeycombe, R. Steels: Microstructure and Properties, 3rd ed.; Elsevier: Oxford, UK, 2006; p. 287.

3. Bhadeshia, H. Bainite in Steels, 2nd ed.; IOM Communications: London, UK, 2001; pp. 1-454.

4. Laitinen, R. Improvement of Weld HAZ Toughness at Low Heat Input by Controlling the Distribution of M-A Constituents. Ph.D. Thesis, University of Oulu, Oulu, Finland, 2006.

5. Zhou, B.W.; Li, G.Q.; Wan, X.L.; Li, Y.; Wu, K. In-situ observation of grain refinement in the simulated heat-affected zone of high strength low alloy steel by Zr-Ti combined deoxidation. Met. Mater. Int. 2016, 22, 267-275. [CrossRef]

6. Li, Y.; Crowther, D.N.; Green, M.J.W.; Mitchell, P.S.; Baker, T.N. The effect of vanadium and niobium on the properties and microstructure of the intercritically reheated coarse grained heat affected zone in low carbon microalloyed steels. ISIJ Int. 2001, 41, 46-55. [CrossRef]

7. Bonnevie, E.; Ferriere, G.; Ikhlef, A.; Kaplan, D.; Orain, J.M. Morphological aspects of martensite- austenite constituents in intercritical and coarse grain heat affected zones of structural steels. Mater. Sci. Eng. A 2004, 385, 352-358. [CrossRef]

8. Yu, L.; Wang, H.H.; Wang, X.L.; Huang, G.; Hou, T.P.; Wu, K.M. Improvement of impact toughness of simulated heat affected zone by addition of aluminium. Mater. Sci. Technol. 2014, 30, 1951-1958. [CrossRef]

9. Kim, S.H.; Bang, C.Y.; Bang, K.S. Weld metal impact toughness of electron beam welded $9 \% \mathrm{Ni}$ steel. J. Mater. Sci. 2001, 36, 1197-2000. [CrossRef] 
10. Keehan, E.; Andren, H.O.; Karlsson, L.; Murugananth, M.; Bhadeshia, H. Microstructural and mechanical effects of nickel and manganese on high strength steel weld metals. In Proceedings of the Sixth International Conference, Trend in Welding Research, Pine Mountain, GA, USA, 15-19 April 2002; pp. 695-700.

11. Suh, D.W.; Park, S.J.; Kim, S.J. Influence of $\mathrm{Cr}$ and Ni on Microstructural Evolution during Heat Treatment of Low-Carbon Transformation Induced Plasticity Steels. Metall. Mater. Trans. A 2008, 39A, 2015-2019. [CrossRef]

12. Huang, G.; Wan, X.; Wu, K.M. Effect of Cr content on microstructure and impact toughness in the simulated coarse-grained heat-affected zone of high-strength low-alloy steels. Steel Res. Int. 2016, 87, 1426-1434. [CrossRef]

13. Huang, G.; Wan, X.L.; Wu, K.M.; Isayev, O.; Hress, O.; Rodionova, A.; Sirzadi, A. Effect of Cu addition on microstructure and impact toughness in the simulated coarse-grained heat-affected zone of high-strength low-alloy steels. Mater. Sci. Technol. 2017, 33, 602-614. [CrossRef]

14. Wan, X.L.; Wu, K.M.; Nune, K.C.; Li, Y.; Chen, L. In-situ observation of acicular ferrite formation and grain refinement in the simulated heat-affected zone of steel. Sci. Technol. Weld. Join. 2015, 20, 254-263. [CrossRef]

15. Matsuda, F.; Li, Z.; Bernazovsky, P.; Ishihara, K.; Okada, H. Investigation on the behaviour of the M-A constituent in simulated HAZ of HSLA steels. Weld. World 1991, 29, 307-313.

16. Wan, X.L.; Wu, K.M.; Huang, G.; Nune, K.C.; Li, Y.; Cheng, L. Toughness improvement by Cu addition in the simulated coarse-grained heat-affected zone of high-strength low-alloy steels. Sci. Technol. Weld. Join. 2016, 21, 295-302. [CrossRef]

17. Wan, X.L.; Wu, K.M.; Cheng, L.; Wei, R. In-situ observations of acicular ferrite growth behavior in the simulated coarse-grained heat-affected zone of high-strength low-alloy steels. ISIJ Int. 2015, 55, 679-685. [CrossRef]

18. Shi, M.; Zhang, P.; Zhu, F. Toughness and microstructure of coarse grain heat affected zone with high heat input welding in Zr-bearing low carbon steel. ISIJ Int. 2014, 54, 188-192. [CrossRef]

(C) 2018 by the authors. Licensee MDPI, Basel, Switzerland. This article is an open access article distributed under the terms and conditions of the Creative Commons Attribution (CC BY) license (http:/ / creativecommons.org/licenses/by/4.0/). 